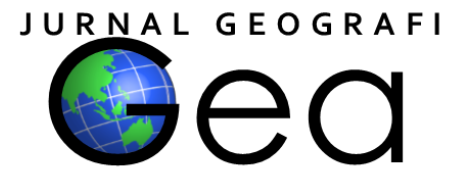

\title{
VERTICAL ACCURACY ASSESSMENT ON SENTINEL-1, ALOS PALSAR, AND DEMNAS IN THE CIATER BASIN
}

\author{
Haikal Muhammad Ihsan', ${ }^{1}$ Sahid $^{2}$ \\ ${ }_{1,2}$ Universitas Pendidikan Indonesia \\ 1'haikalmihsan@upi.edu, ${ }^{2}$ maani.sahid@gmail.com
}

\begin{abstract}
Vertical accuracy in DEM (Digital Elevation Model) products is very important for an earth study. There are medium resolution DEM data products that can be accessed freely such as DEMNAS, Alos Palsar 12.5m and Sentinel-1. The aim of this study is to measure the vertical accuracy of the DEMNAS, Alos Palsar $12.5 \mathrm{~m}$ and Sentinel-1 data products by considering the slope angle classification and using two different GIS software. Vertical accuracy is measured using 848 spotheight points, by calculating the RMSE (Root Mean Square Error) value of each DEM product with different software. Based on the research, it was found that DEMNAS is a DEM product that has the best comparability value than Alos Palsar and Sentinel-1, because it has the smallest RMSE value. Slope angle class gives different values of bias against absorption and reflection of electromagnetic waves. Flat to moderate steep slope angles tend to be better at absorbing and reflecting electromagnetic waves. The software differences in the analysis did not significantly affect the altitude of the DEM and RMSE high points. The spotheight point needs to be reaccurated with a more detailed geodetic point, to get maximum results.
\end{abstract}

Keywords: DEMNAS, Alos Palsar, Sentinel-1, Vertical Accuracy

\section{INTRODUCTION}

DEM (Digital Elevation Model) is an altitude model that is widely applied in various scientific disciplines (Apeh et al, 2019) such as topography, geomorphology, disaster, urban and glacier observation (Pope et al, 2007). Several topographic and geomorphological elements can be generated through DEM such as channels and hillslopes, as well as other terrain attributes, namely slope angle, aspect, and topographic wetness index (Gdulova et al, 2020). There are DEM data that can be accessed freely such as SRTM (Shuttle Radar Topography Mission), ALOS (Advanced Land Observing Satellite), ASTER (Advanced Spaceborne Thermal Emission) with a resolution of 30m (Zhang et al, 2019).

The availability of high and medium resolution DEM data is quite difficult to freely access. Some data that can be built into a high resolution DEM is worldview-2 with a resolution of $0.52 \mathrm{~m}$ panchromatic and $1.8 \mathrm{~m}$ multispectral at nadir (Wang et al, 2019), and the results of aerial photographs are built into DEM with a resolution of $0.1 \mathrm{~m}$ ( Ajibola et al, 2019). Sentinel-1 is one of the remote sensing data that can be extracted into medium resolution DEM (Ayubmohammadi et al, 2018). Indonesia has DEM data that can be accessed freely with a resolution of 0.27 arcsecond or $8.1 \mathrm{~m}$ issued by the BIG (Geospatial Information Agency) institution, namely DEMNAS. There is also Alos Palsar with a $12.5 \mathrm{~m}$ resolution that can be accessed freely.

Vertical accuracy needs conducted before the DEM data is used to generate hydrogeological information. Accuracy is the closeness of the observation to the true value (Maune et al, 2001; Mukherjee et al, 2013). The vertical accuracy of the DEM is calculated based on the difference between the altitude value of the DEM and other altitude sources that have higher accuracy (Soliman et al, 2019; 
Grohman, 2018). Accuracy is carried out on DEM to determine the exact similarity of values with several geodetic measurement points (Lazecky et al, 2018). DEM vertical accuracy is influenced by the morphological characteristics of the terrain and terrain roughness (Mukherjee et al, 2013). The lower the vertical accuracy of the DEM used, the lower the quality and accuracy of slope and aspect angles, so that it will affect the quality of studies extracted from DEM (Soliman et al, 2019).

DEM studies can be carried out by several GIS (Geographic Information System) software. Each software has its own algorithm for analysis, one of which is how to use clip tools. It is assumed that different cutting algorithms can produce different area and height values for the DEM raster value. The difference in area and height value will affect the value of the vertical study. There are several software available freely such as QGIS, as for the paid software that is commonly used, namely ArcGIS.

This study aims to examine the vertical accuracy of three types of freely accessible medium resolution DEMs, namely Sentinel-1 (extracted into DEM), Alos Palsar 12.5m and DEMNAS, by utilizing and comparing the results of two software studies namely QGIS and ArcGIS. The level of accuracy of the DEM has a direct impact on the calculation of a study, so it is important to choose the most appropriate DEM by considering the objectives, accuracy requirements and the scale of the study (Alganci et al, 2018). Vertical accuracy is carried out for each different classification of slope angles. Slope angle is used because it is often one of the parameters in various earth studies. This research can be a consideration for selecting DEM data in earth analysis.

\section{RESEARCH METHOD}

\section{Study Area}

This research was conducted in the Ciater Basin area, because it has varied topography and slope angles. The vertical accuracy study requires varied terrain to determine the accuracy of the DEM data. The ciater basin is at coordinates $6^{\circ} 35^{\prime} 0^{\prime \prime} \mathrm{S}-6^{\circ}$ $49^{\prime} 0 " \mathrm{~S}$ and $107^{\circ} 24^{\prime} 30^{\prime \prime} \mathrm{E}-107^{\circ} 49^{\prime} 0^{\prime \prime} \mathrm{E}$. The Ciater Basin is close to the existence of active volcanoes so that it is located on the highlands in the south and east and lowlands in the north. The functional boundaries of the Ciater Basin are obtained from the Geological Agency and processed through digitizing ArcGIS software (Figure 1 Ciater Basin Map).

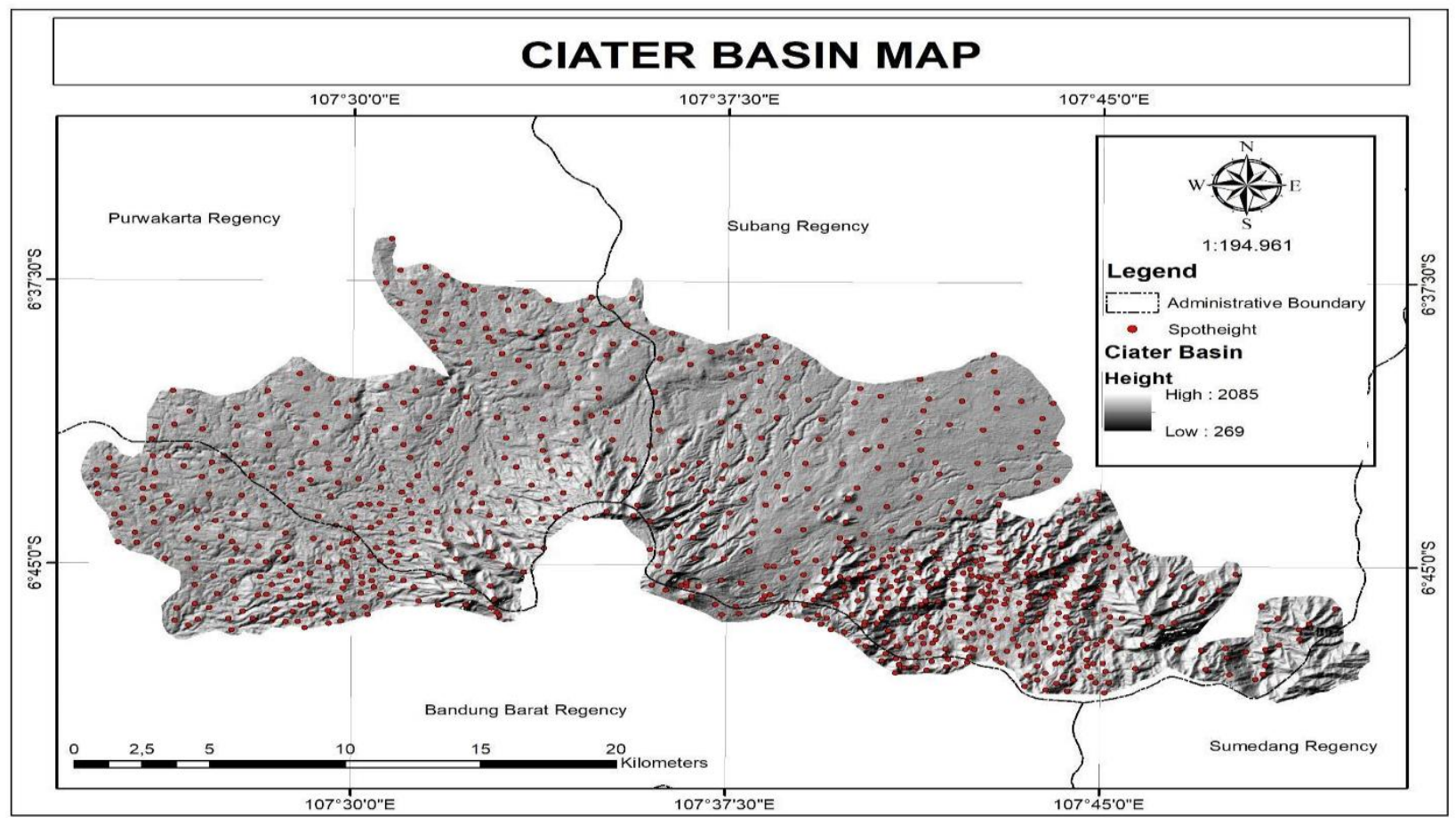

Figure 1. Ciater Basin Map 


\section{Data}

Based on BIG (Geospatial Information Agency) DEMNAS or DEM Nasional built from several data sources including IFSAR data (5m resolution), TERRASAR-X $(5 \mathrm{~m}$ resolution) and ALOS PALSAR $(11.25 \mathrm{~m}$ resolution), by adding masspoint data from stereo-plotting results. The spatial resolution of DEMNAS is 0.27-arcsecond, using the EGM2008 vertical datum.

DEMNAS is satellite data produced by BIG. DEMNAS can be accessed on the following official BIG website on the internet namely http://tides.big.go.id/DEMNAS/. Validation of DEM accuracy using spotheight data sourced from https://tanahair.indonesia.go.id/portal-web. The spotheight data used are 848 points scattered in the Ciater Basin area.

\section{Analysis Technique}

\subsection{DEM Analysis}

DEM development on Sentinel-1 is conducted by SNAP (Sentinel Application Platform) software. There are several stages such as registering scenes, calculating baselines, creating interferograms, extracting phase information, geometric correction, atmospheric correction, converting the differential phase to absolute phase, phase unwrapping, conversion of phase to altitude and absolute height correction. DEMNAS and Alos Palsar are already in the form of DEM products and are ready to be analyzed. Some DEM products need to have the same datum in order for maximum product analysis. Spotheight will be processed by ArcGIS and QGIS software to determine each height on Sentinel-1, Alos Palsar and DEMNAS with raster to point extract tools.

\subsection{Vertical Accuracy}

The difference in vertical accuracy is carried out by analyzing each spotheight at different slopes and relief. This study was conducted to determine the vertical accuracy of Sentinel-1, Alos Palsar, and DEMNAS based on the slope classification output (Table 1). Slope and relief were made using ArcGIS software with slope tools, then classified using reclassify tools. The vertical accuracy is known by using the RMSE (Root Mean Square Error) and STDEV (Standard Deviation) statistics. The imagery of the Sentinel-1, alos palsar and DEMNAS satellites will be compared with geodesic points to determine the accuracy and precision of these products.

$R M S E= \pm \sqrt{\frac{1}{n} \sum_{i=1}^{n}\left[\left(x_{i}-y_{i}\right)^{2}\right]}$

$S T D=\sqrt{\frac{1}{n-1} \sum_{i=1}^{n}\left[\left(x_{i}-y_{i}\right)-(\underline{x}-\underline{y})\right]^{2}}$

Wheres:

RMSE = Root mean square error,

STDEV = Standard deviation

$\mathrm{N}=$ The number of GCPs

$x_{i} \quad=$ DEM elevation at the referenced point $\mathrm{i}$,

$y_{i}=$ DEM elevation at the point $\mathrm{i}$

$\underline{x}=$ DEM elevation at the referenced point i,

$\underline{y}=$ DEM elevation at the point $\mathrm{i}$

Vertical accuracy is performed on each slope classification based on Van zuiddam (1985) (table 1). Slopes are built from Sentinel-1, Alos Palsar and DEMNAS using the ArcGIS application on tools slopes with degree specifications. Slopes are used because they are often one of the parameters in various earth studies. Slopes are an important component in hydrogeological studies with respect to DEM data.

Table 1. Slope Classification

\begin{tabular}{cccc}
\hline Classification & $\begin{array}{c}\text { Slope } \\
(\%)\end{array}$ & $\begin{array}{c}\text { Height } \\
(\mathrm{m})\end{array}$ & $\begin{array}{c}\text { Slope } \\
\left({ }^{\circ}\right)\end{array}$ \\
\hline Flat & $0-2$ & $<5$ & $0-2$ \\
Gently Slope & $2-7$ & $5-50$ & $2-4$ \\
Sloping & $7-15$ & $25-75$ & $4-8$ \\
Moderately & $15-$ & $75-200$ & $8-16$ \\
Steep & 30 & & \\
Steep & $16-$ & $200-$ & $16-35$ \\
Very Steep & 35 & 500 & \\
& $35-$ & $500-$ & $35-55$ \\
& 140 & 1000 &
\end{tabular}




\begin{tabular}{ccc}
$\begin{array}{c}\text { Extremely } \\
\text { Steep }\end{array}$ & $>140>1000>55$ \\
\hline & Sumber: Van Zuiddam, 1985
\end{tabular}

\section{FINDINGS AND DISCUSSION}

\section{DEM Analysis}

DEM data development analysis was carried out on the Sentinel-1 SAR (Synthetic Aperture Radar) data. DEMNAS and Alos Palsar data can be used directly, because they are included in the DEM data type. The sentinel-1 SAR data used is the VH and VV polarization which was acquired on April 23, 2020. The sentinel-1 class belongs to the Interferometric Wide Swath Level 1 product. Based on the results of the analysis, it was found that the DEM built from sentinel-1 has a spatial resolution of $14 \mathrm{~m}$. DEMNAS has a resolution of 0.27 -arcsecond which when converted to $8.1 \mathrm{~m}$. The Alos Palsar used has a spatial resolution of $12.5 \mathrm{~m}$.

\section{Vertical Slope Accuracy}

The extraction of altitude values from the Sentinel-1, Alos Palsar, and DEMNAS data products has an altitude point value that is close to the spotheight high point value (Figure 3). Vertical accuracy was performed on each slope based on Van Zuiddam (1985) with a total of 848 spotheight points.

Each slope has a different total spotheight points with the highest number in the moderately steep class, namely 279 points. In the extremely steep class, spot height points were not found, because the steepness was very high, making it difficult to measure (Table 1).
Therefore, the vertical measurement of accuracy is carried out on the classification of flat $\left(0^{\circ}-2^{\circ}\right)$, gently slope $\left(2^{\circ}-4^{\circ}\right)$, sloping (4 $\left.\circ-8^{\circ}\right)$, moderately steep $\left(8^{\circ}-16^{\circ}\right)$, steep ( 16 $\left.{ }^{\circ}-35^{\circ}\right)$ and very steep $\left(35^{\circ}-55^{\circ}\right)$.

A good DEM data product has an RMSE value that is close to 0 because the smaller it is close to 0 , the better the equivalence for DEM data products. Based on the results of the analysis, DEMNAS is a DEM product with an RMSE (Root Mean Square Error) value that is close to a value of 0 in the flat slope angle class (7.65), gently slope (8.44), sloping (8.71), and moderately steep (9.22) (Table 1). Alos Palsar DEM data product has the smallest RMSE value in the slope class of steep (12.04) and very steep (10.41). DEMNAS has a higher spatial resolution than Alos Palsar, but has a higher RMSE value in the steep (26.29) and very steep (21.39) slope classes. This condition occurs in the processed products of two software QGIS and ArcGIS.

Absorption and reflection of electromagnetic waves from satellites on the earth's surface produce different refractive values. In the step and very steep slope class, the bias value is the reason the Alos Palsar DEM data product has a smaller RMSE value than DEMNAS. The shape of the earth's visual field in a flat and steep area has a difference in the ability of the waves to absorb and reflect the spectral values. 


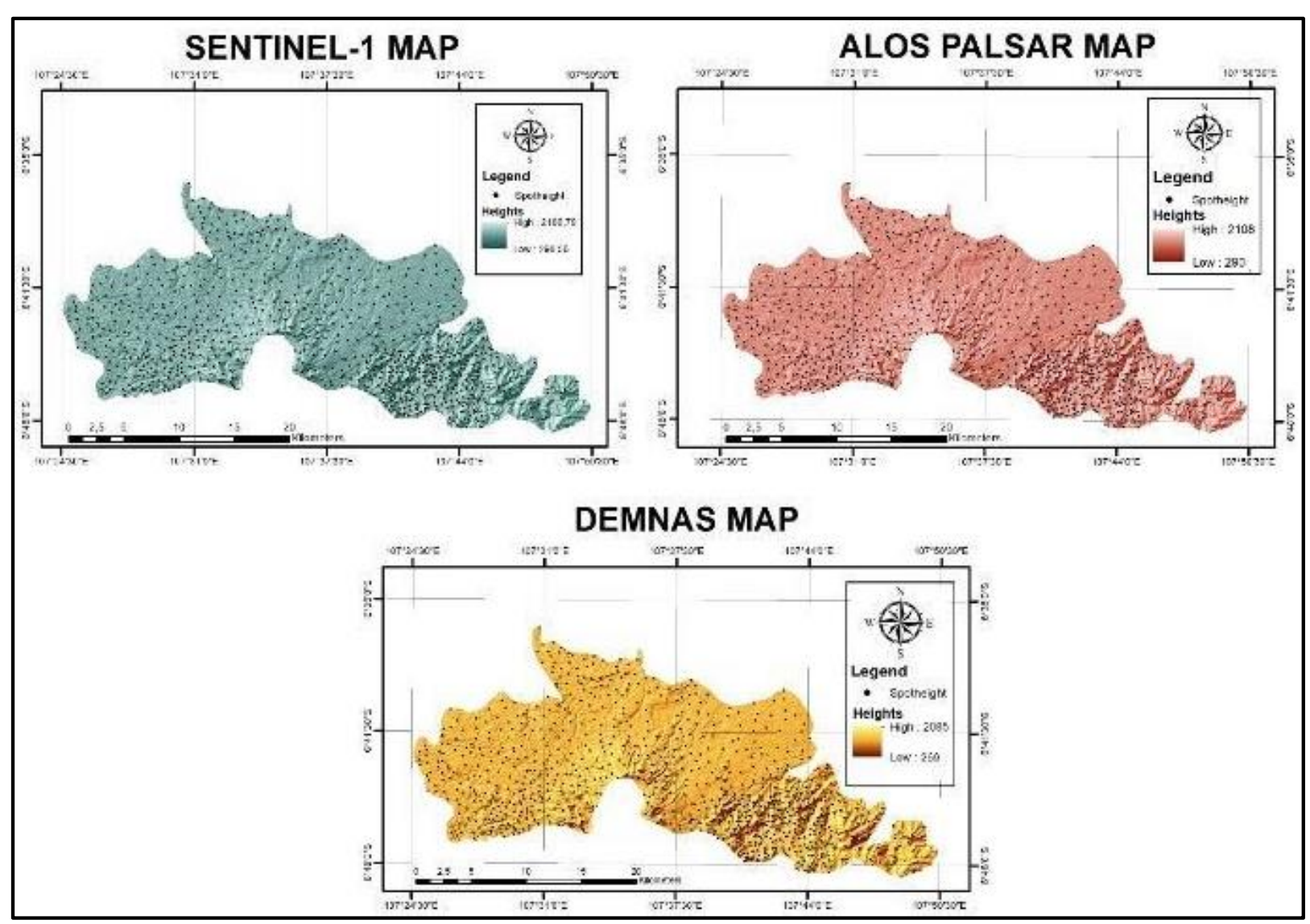

Figure 2. The results of the DEM (Digital Elevation Model) clip by ArcGIS
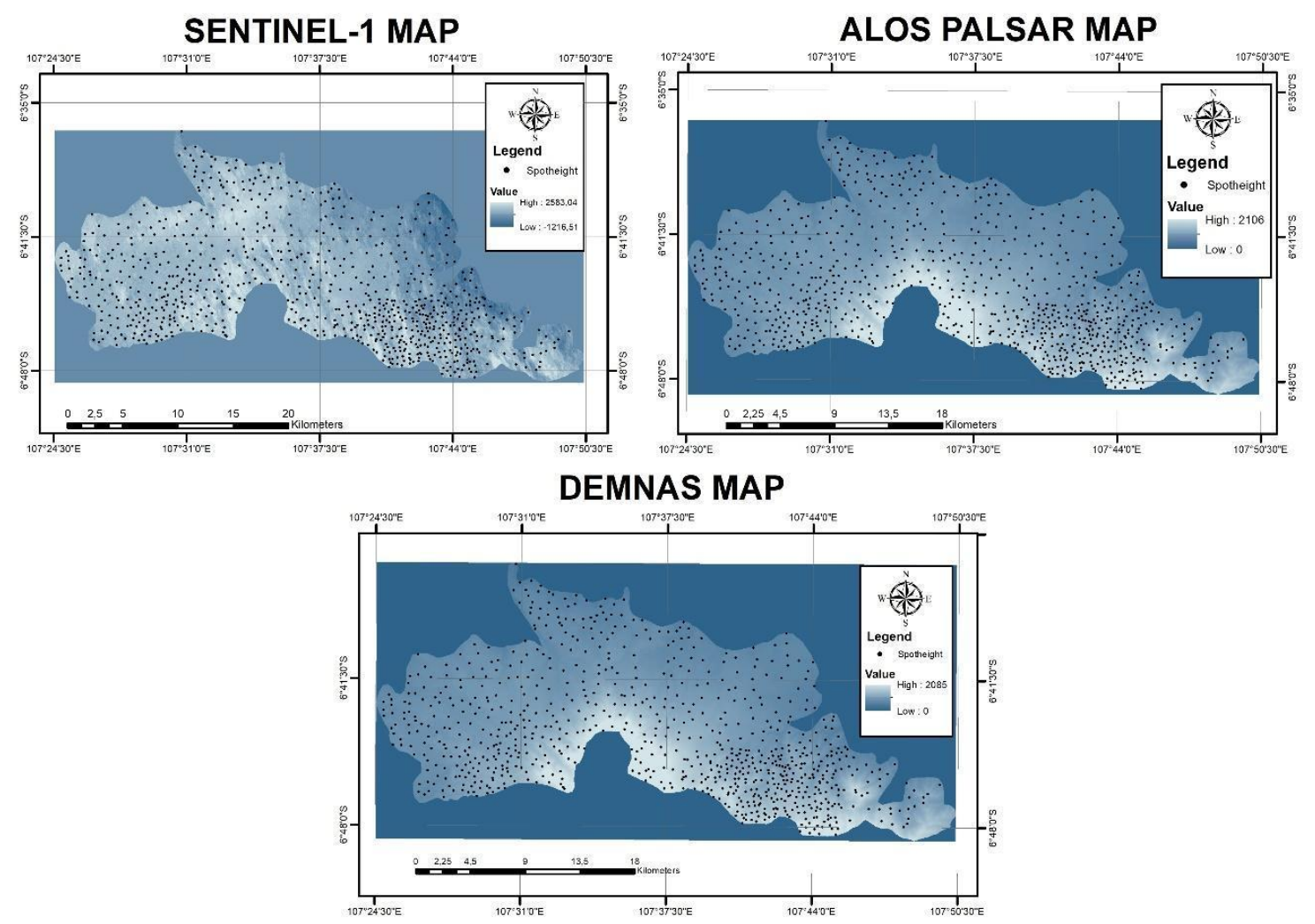

Figure 3. The results of the DEM (Digital Elevation Model) clip by QGIS 
Vertical Accuracy

Based on research, DEMNAS is a DEM product that has the best equivalent value of Alos Palsar and Sentinel-1. DEMNAS has a smaller RMSE value (12.51) than Alos Palsar (20.07) and Sentinel-1 (20.02) (Table 2). This condition is based on the analysis of two different softwares. The spatial resolution can be an indicator of the accuracy of a DEM product.
The higher the spatial resolution, the better the DEM product used. The spatial resolution precisely affects the scale of the object to be studied as well as the information presented on the map. The RMSE value which tends to be large is assumed to occur because of the accuracy of the spotheight point measurement, because the spotheight point is the height reference in the vertical accuracy study. The high points of the spotheight, DEMNAS, Alos Palsar and Sentinel-1 have a regular chart pattern (Figure 4).

Table 2. Measurement Results at Each Slope Angle

\begin{tabular}{|c|c|c|c|c|c|c|c|}
\hline \multirow{2}{*}{ Slope } & \multirow{2}{*}{ Software } & \multirow{2}{*}{$\begin{array}{c}\text { Spotheight } \\
\text { total }\end{array}$} & \multirow{2}{*}{ DEM } & \multirow{2}{*}{ RMSE } & \multicolumn{3}{|c|}{ Heights } \\
\hline & & & & & Max & Min & Average \\
\hline \multirow{7}{*}{$\begin{array}{l}\text { Flat } \\
\left(0^{\circ}-2^{\circ}\right)\end{array}$} & \multirow{3}{*}{ ArcGIS } & \multirow{7}{*}{48} & DEMNAS & 7,654711775 & 2085 & 453 & 744,7 \\
\hline & & & Alos Palsar & 23,06826068 & 2106 & 478 & 766,3 \\
\hline & & & Sentinel & 23,07522904 & 2101,9 & 478,0 & 765,7 \\
\hline & & & Spotheight & - & 2086,2 & 449 & 744,5 \\
\hline & \multirow{3}{*}{ QGIS } & & DEMNAS & 7,641146011 & 2085,0 & 453 & 744,7 \\
\hline & & & Alos Palsar & 23,12440235 & 2104,0 & 478 & 766,2 \\
\hline & & & Sentinel & 22,89884673 & 2104,8 & 477,477 & 766,0 \\
\hline \multirow{7}{*}{$\begin{array}{l}\text { Gently Slope } \\
\left(2^{\circ}-4^{\circ}\right)\end{array}$} & \multirow{3}{*}{ ArcGIS } & \multirow{7}{*}{147} & DEMNAS & 8,43836567 & 1883 & 385 & 803,9 \\
\hline & & & Alos Palsar & 22,12831352 & 1903 & 403 & 824,8 \\
\hline & & & Sentinel & 22,0806984 & 1899,6 & 404,0 & 824,8 \\
\hline & - & & Spotheight & - & 1892,0 & 378,4 & 804,4 \\
\hline & \multirow{3}{*}{ QGIS } & & DEMNAS & 8,42414909 & 1883,0 & 385,0 & 803,9 \\
\hline & & & Alos Palsar & 22,38606098 & 1905,0 & 405,0 & 825,1 \\
\hline & & & Sentinel & 22,11935396 & 1904,4 & 404,4 & 824,8 \\
\hline \multirow{7}{*}{$\begin{array}{l}\text { Sloping } \\
\left(4^{\circ}-8^{\circ}\right)\end{array}$} & \multirow{3}{*}{ ArcGIS } & \multirow{7}{*}{264} & DEMNAS & 8,709254072 & 2076 & 376 & 865,3 \\
\hline & & & Alos Palsar & 21,41082393 & 2100 & 394 & 885,6 \\
\hline & & & Sentinel & 21,74034288 & 2099,03 & 397,836 & 885,8 \\
\hline & - & & Spotheight & - & 2079,54 & 370,0 & 866,0 \\
\hline & \multirow{3}{*}{ QGIS } & & DEMNAS & 8,777681822 & 2077 & 376,0 & 865,3 \\
\hline & & & Alos Palsar & 21,70813275 & 2098 & 395,0 & 885,9 \\
\hline & & & Sentinel & 21,43906263 & 2099,03 & 394,8 & 885,6 \\
\hline \multirow{7}{*}{$\begin{array}{c}\text { Moderately } \\
\text { Steep } \\
\left(8^{\circ}-16^{\circ}\right)\end{array}$} & \multirow{3}{*}{ ArcGIS } & \multirow{7}{*}{279} & DEMNAS & 9,225916758 & 2024 & 275 & 1002,2 \\
\hline & & & Alos Palsar & 17,32017515 & 2045 & 295 & 1020,5 \\
\hline & & & Sentinel & 18,22239317 & 2044,2 & 294,981 & 1021,5 \\
\hline & - & & Spotheight & - & 2024,9 & 266,7 & 1005,8 \\
\hline & \multirow{3}{*}{ QGIS } & & DEMNAS & 9,200668897 & 2024 & 275,0 & 1002,4 \\
\hline & & & Alos Palsar & 18,01973237 & 2046 & 295,0 & 1021,2 \\
\hline & & & Sentinel & 17,45584265 & 2044,78 & 295,0 & 1020,6 \\
\hline \multirow{2}{*}{$\begin{array}{c}\text { Steep } \\
\left(16^{\circ}-35^{\circ}\right)\end{array}$} & \multirow{2}{*}{ ArcGIS } & \multirow{2}{*}{108} & DEMNAS & 26,2931719 & 2067 & 586 & 1228,0 \\
\hline & & & Alos Palsar & 19,04200498 & 2092 & 601 & 1248,3 \\
\hline
\end{tabular}




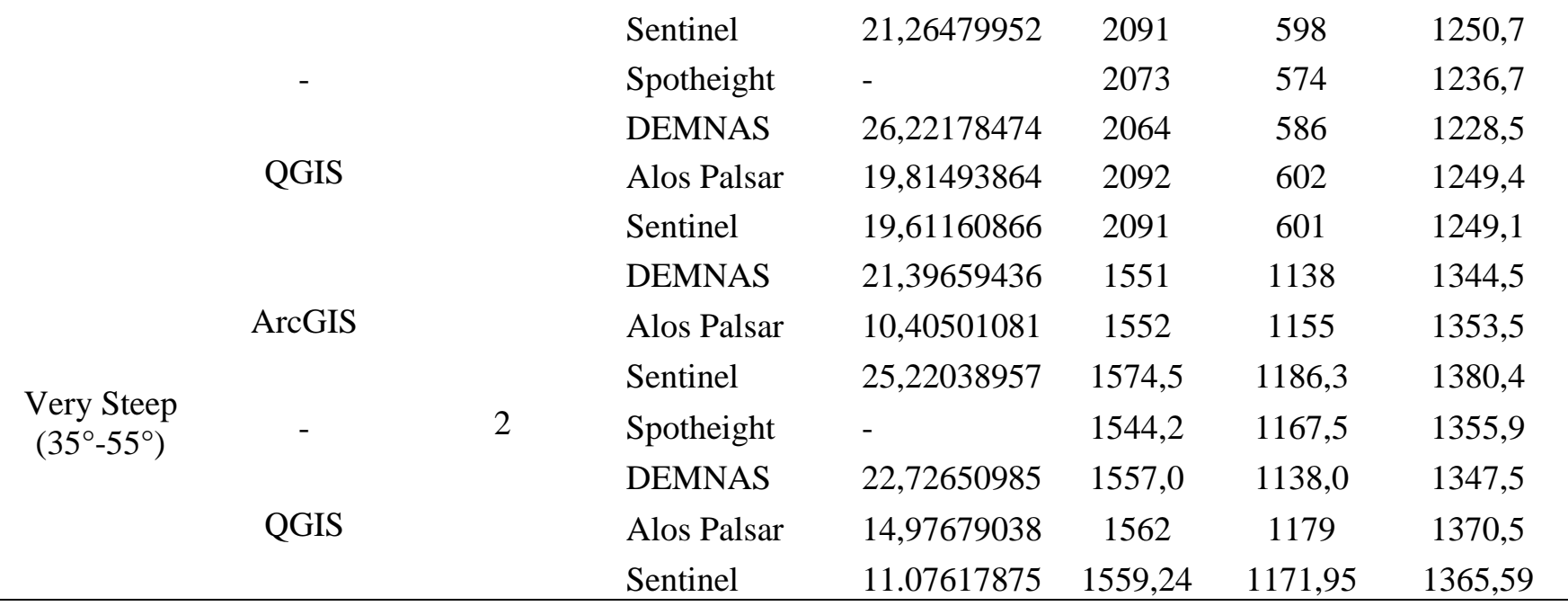

\section{Height DEM and Spotheight}

2500

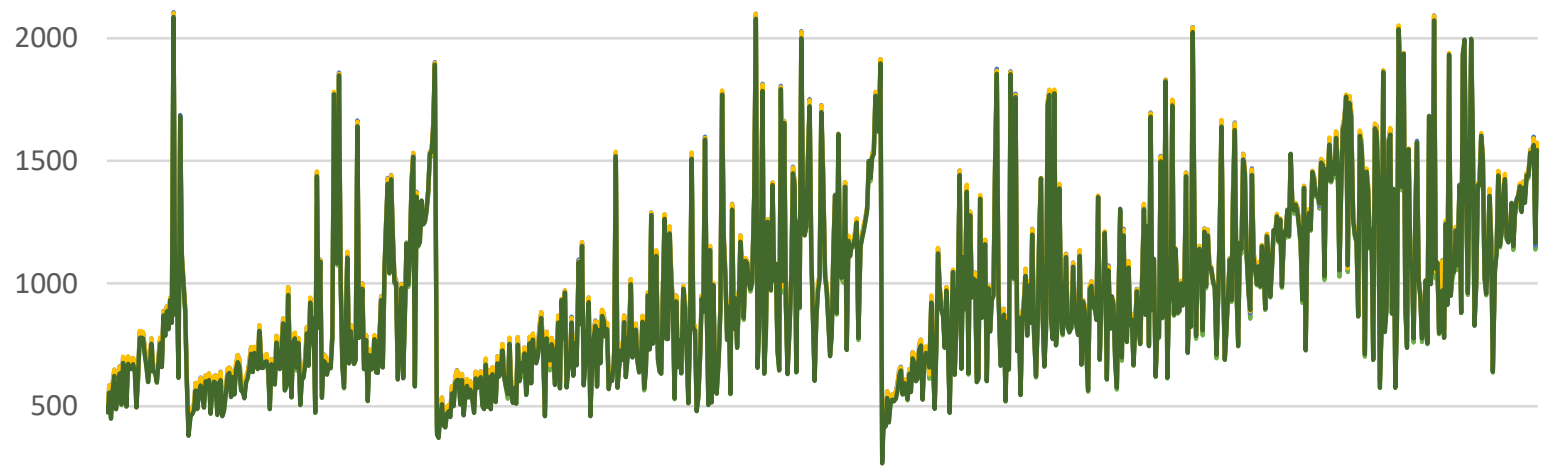

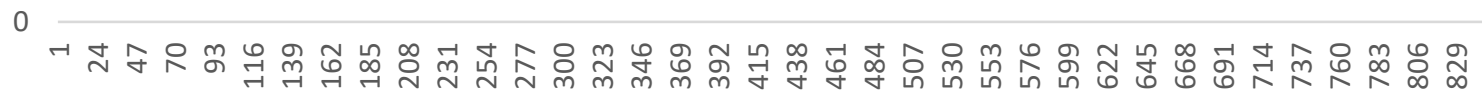

—DEMNAS - Alos Palsar Sentinel-1 Spotheight

Figure 4. Graph of DEM and Spotheight Height 


\section{ArcGIS}
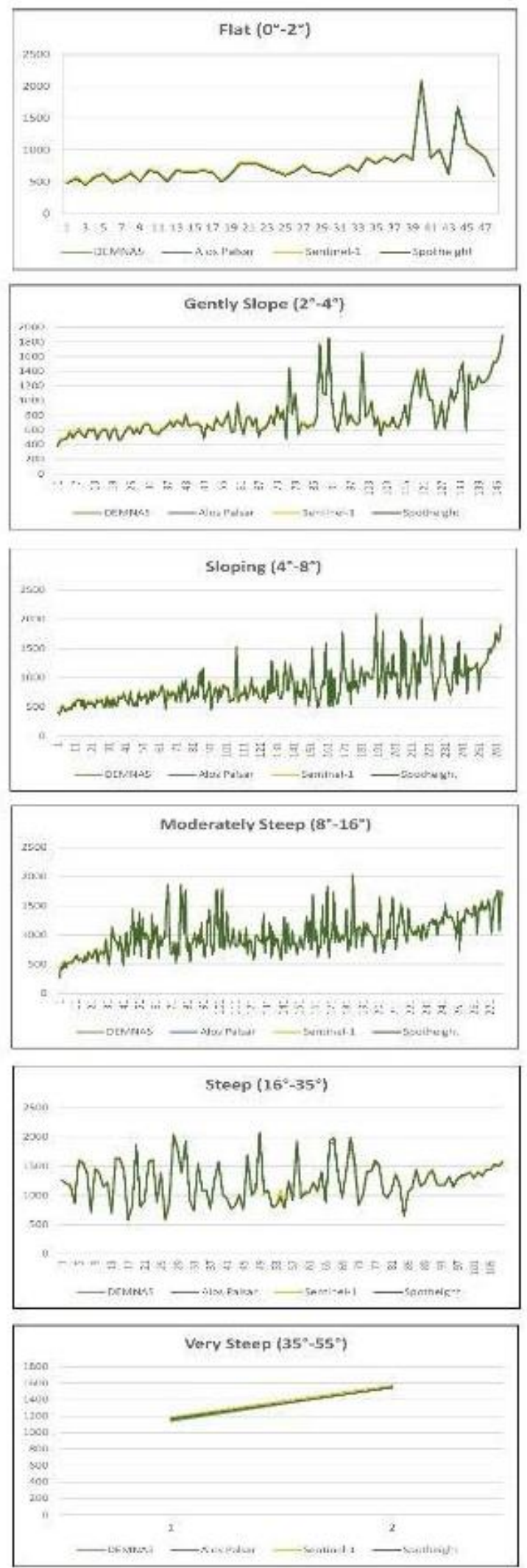

QGIS
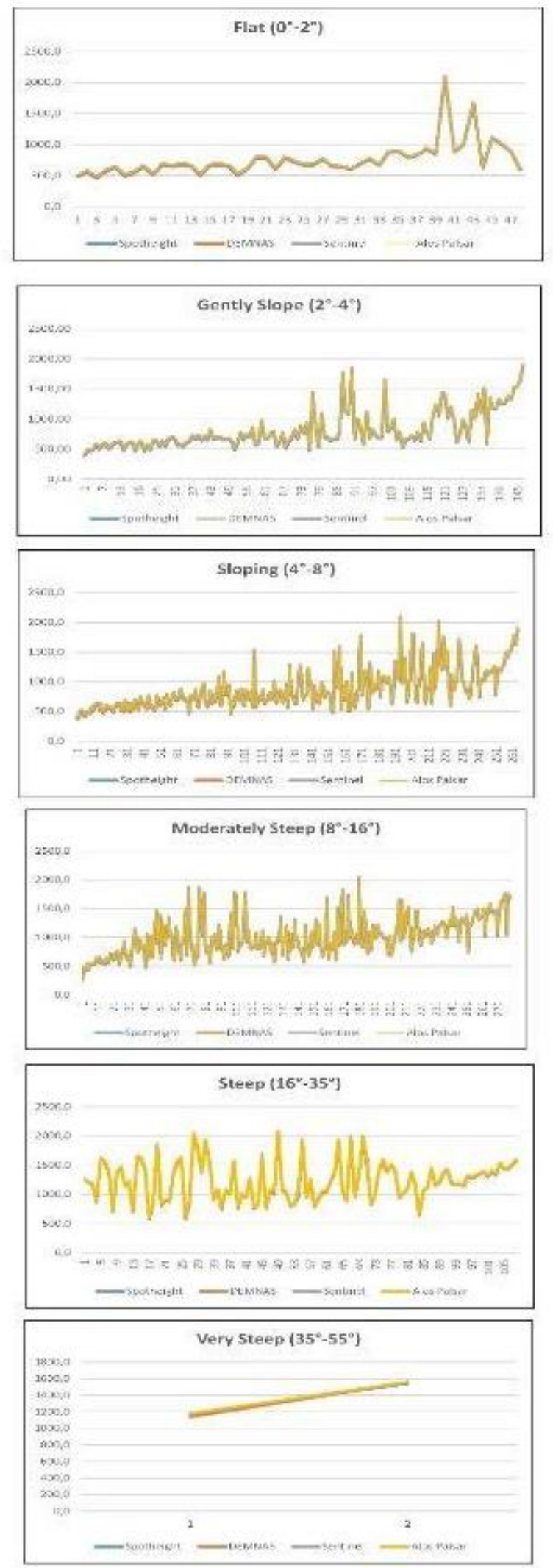

Figure 5. Height Graph at Slope Angle 


\section{CONCLUSIONS}

Slopes give different values of bias to the absorption and reflection of electro-magnetic waves. Flat to moderately steep slopes tend to be better at absorbing and reflecting electromagnetic waves. DEMNAS is a DEM product with the best accuracy than Alos Palsar and Sentinel-1. DEMNAS has a smaller RMSE value than Alos Palsar and Sentinel-1, so it has the best compatibility for a slope-based study. Spatial resolution is one of the indicators of DEMNAS having good accuracy. In very steep slope areas, a more detailed vertical accuracy study is required. The spotheight point needs to be re-accurate with a more detailed geodetic point, to get maximum results. The difference in software in the analysis does not really affect the altitude and high point RMSE values.

\section{REFERENCES}

A, mohammadi. B, B, Ahmad. H, Shahabi. (2018). Extracting Digital Elevation Model (Dem) From Sentinel-1 Satellite Imagery: Case Study A Part Of Cameron Highlands, Pahang, Malaysia. International Journal of Management and Applied Science, ISSN: 2394-7926. Vol 4. Issue 9. http://iraj.in

A, Pope. T, Murray. \& A, Luckman., (2007). DEM quality assessment for quantification of glacier surface change. Annals of Glaciology. Vol, 46. pp, 198194.

DOI: https://doi.org/10.3189/1727564077828 $\underline{71792}$

A, Schubert. D, Small. N, Miranda. D, Geudtner. and E, Meier. (2015). Sentinel-1A Product Geolocation Accuracy: Commissioning Phase Results. Remote Sensing, MDPI. vol 7, pp 9431-9449. doi:10.3390/rs70709431

A, Soliman. \& L, Han., (2019). Effects of vertical accuracy of digital elevation model (DEM) data on automatic lineaments extraction from shaded
DEM. Advances in Space Research, Vol, 64. pp, 603-622. https://doi.org/10.1016/j.asr.2019.05.00 $\underline{9}$

I, I, Ajibola. S, Mansor. B, Pradhan. \& H, Z, Mohd. Shafri., (2019). Fusion of UAVbased DEMs for vertical component accuracy improvement. Measurement. Vol, 147. pp, 106795. https://doi.org/10.1016/j.measurement.2 $\underline{019.07 .023}$

J, Chen. F, Günther. G, Grosse. L, Liu. and H, Lin. (2018). Sentinel-1 InSAR Measurements of Elevation Changes over Yedoma Uplands on Sobo-Sise Island, Lena Delta. Remote Sensing, MDPI, vol $10 . \quad \mathrm{p} \quad 1152$. https://doi.org/10.3390/rs10071152.

K, Gdulová. J, Marešová. \& V, Moudrý., (2020). Accuracy assessment of the global TanDEM-X digital elevation model in a mountain environment. Remote sensing of environment. Vol, 241.

$\mathrm{pp}$, 111724. https://doi.org/10.1016/j.rse.2020.11172 $\underline{4}$.

K, Zhanga. D, Gannc. M, Rossa. Q, Robertsone. J, Sarmientob. S, Santanac. J, Rhomef. \& C, Fritzf., (2019). Accuracy assessment of ASTER, SRTM, ALOS, and TDX DEMs for Hispaniola and implications for mapping vulnerability to coastal flooding. Remote sensing of Environment. Vol, 225. pp, 290-306.

https://doi.org/10.1016/j.rse.2019.02.02 $\underline{8}$.

M, Lazeckýa. I, Hlaváčováb. J, Martinoviča. \& A, M, RuizArmenteros. (2018). Accuracy of Sentinel-1 Interferometry Monitoring System based on Topography-free Phase Images. Procedia Computer Science. Vol, 138, $\mathrm{pp}$

310-317. 
https://doi.org/10.1016/j.procs.2018.10. $\underline{044 .}$

O, I, Apeh. V, N, Uzodinma. E, S, Ebinne. E, C, Moka. \& E, U, Onah., (2019). Accuracy Assessment of Alos W3d30, Aster Gdem and Srtm30 Dem: A Case Study of Nigeria, West Africa. Journal of Geographic Information system, Vol, 11. $\mathrm{pp}$,

DOI: $10.4236 /$ jgis.2019.112009

S, Mukherjee. P, K, Joshi. S, Mukherjee. A, Ghosh. R, D, Garg. \& A, Mukhopadhyay. (2013). Evaluation of vertical accuracy of open source Digital Elevation Model (DEM). International Journal of Applied Earth Observation and Geoinformation. Vol, 21. pp, 205217.

https://doi.org/10.1016/j.jag.2012.09.00 4 .
S, Wang. Z, Ren. C, Wu. Q, Lei. W, Gong. Q, Ou. H, Zhang. G, Ren. \& C, Li., (2019). DEM generation from Worldview-2 stereo imagery and vertical accuracy assessment for its application in active tectonics. Geomorphology. 336, 107118.

https://doi.org/10.1016/j.geomorph.201 $\underline{9.03 .016}$

U, Alganci. B, Besol \& E, Sertel., (2018). Accuracy Assessment of Different Digital Surface Models. International Journal of Geo-Information. Vol, 7. pp. 114.

https://doi.org/10.3390/ijgi7030114.

Zuidam, R.A. Van., 1985. Aerial PhotoInterpretation Terrain Analysis and Geomorphology Mapping. Smith Publisher The Hague. 